\title{
Valve-sparing aortic root replacement in patients after a previous operation for acute type $A$ aortic dissection
}

\author{
Rainer G. Leyh, MD, Stefan Fischer, MD, Arjang Ruhparwar, MD, Mathias Karck, MD, Wolfgang Harringer, MD, \\ and Axel Haverich, MD, Hannover, Germany
}

$\mathrm{T}$ he list of long-term complications after surgical intervention for acute type A aortic dissection includes recurrent dissection, aneurysm formation, and aortic valve regurgitation. Ten years after the initial operation for acute type A dissection, the reoperation rate for these kinds of long-term complications is $13 \%$ to $30 \%$ in the literature. ${ }^{1}$ The diseased aortic root in these patients is commonly treated with the replacement of the aortic valve and ascending aorta with an artificial composite graft carrying a mechanical or biologic valve substitute.

Recently, we have described the feasibility of valve-sparing aortic root replacement in acute type A dissection. ${ }^{2}$ However, no reports are available on the feasibility of valve-sparing aortic root replacement after a previous operation for acute type A dissection involving the aortic root. Here we report on 3 patients who underwent reoperation after an operation for acute type A dissection involving the aortic root, ascending aorta, and aortic arch. In all 3 cases we successfully performed valve-sparing aortic root replacement.

\section{Clinical Summary}

Between May 2000 and May 2001, 3 patients with symptomatic aneurysmal dilation or redissection of the aortic root after a previous operation for acute type A aortic dissection underwent valvesparing aortic root replacement. As the initial operation in all 3 cases, supracommisural replacement of the ascending aorta and reconstruction of the aortic root with gelantine-resorcin-formaldehyde glue (GRF) was performed. Preoperative data and indications for reoperation are summarized in Table 1.

For reoperation, standard cardiopulmonary bypass at moderate hypothermia was used. Aortic arch replacement was performed during moderate hypothermic circulatory arrest. For cerebral protection, selective antegrade cerebral perfusion with cold oxygenated blood was initiated during circulatory arrest. Valve-sparing aortic root replacement was performed as first described by David and Feindel in $1992 .^{3}$

From the Division of Thoracic and Cardiovascular Surgery, Hannover Medical School, Hannover, Germany.

Received for publication May 31, 2001; accepted for publication June 6, 12, 2001.

Address for reprints: Rainer G. Leyh, MD, Division of Thoracic and Cardiovascular Surgery, Hanover Medical School, Carl Neuberg St 1, 30623 Hannover, Germany (E-mail: leyh@thg.mh-hannover.de).

J Thorac Cardiovasc Surg 2002;123:377-8

Copyright (C) 2002 by The American Association for Thoracic Surgery

$0022-5223 / 2002 \$ 35.00+0 \quad \mathbf{1 2 / 5 4 / 1 1 8 6 8 1}$

doi: $10.1067 / \mathrm{mtc} .2002 .118681$
Intraoperative data are depicted in Table 2. In patient 2 the postoperative course was prolonged as a result of paraplegia caused by a thrombosed false lumen in the descending aorta. The other 2 patients recovered uneventfully. The latest postoperative echocardiographic follow-up on patients 1,2, and 3 (at 12, 10, and 1 months, respectively) revealed fully competent aortic valves in all 3 patients.

\section{Discussion}

Here we demonstrate the safety and feasibility of valve-sparing aortic root replacement combined with aortic arch surgery in patients with complex disease of the aortic root after a previous operation for acute type A dissection.

Supracommisural tube graft replacement of the ascending aorta with reconstitution of the aortic wall layers with either biologic glue or incorporation of Teflon felt strips is currently the surgical technique of choice for patients with acute type A dissection. However, a high rate of late aortic root reoperations, mostly for aneurysmal dilation or redissection of the aortic root, is seen. In these cases replacement of the aortic root with a composite graft is currently the surgical intervention of choice. Recently, we have demonstrated that valve-sparing aortic root replacement in acute type A dissection is safe and feasible. ${ }^{2}$ To our knowledge, no data exist that prove the safety of this concept in aortic root reoperations after a previous operation for acute type A dissection. Reoperation on the aortic root in these cases challenges the cardiac surgeon because excessive adhesive scar tissue of the adjacent aortic root tissue develops frequently after reconstruction of aortic wall layers with GRF glue. In some patients so-called blackened leaflet tissue develops when GRF glue was used because of widely unknown chemical processes, which has been explained as a feature of tissue degeneration by Bingley and coworkers. ${ }^{4}$ Because the fate of blackened leaflet tissue is not known, and premature failure of a repair incorporating this tissue can be anticipated, we consider this finding as a contraindication for valve-sparing aortic root replacement. In 1962, Hufnagel and Conrad ${ }^{5}$ pointed out that the main goal of surgical interventions for the treatment of cardiovascular disease should be the complete restoration of physiologic and mechanical normality. This ideal concept, although impossible to reach, can be partially achieved with valve-sparing aortic root surgery. Although our preliminary results are very encouraging, because of the small number of patients, it is impossible to draw definite conclusions on the clinical importance of valve-sparing aortic root replacement after a previous operation for acute type A dissection. However, we believe this technique to be a valuable alternative to the standard technique, which is the replacement of the aortic valve and ascending aorta with an artificial composite graft. Future studies, however, should compare the 
TABLE 1. Preoperative data

\begin{tabular}{|c|c|c|c|c|}
\hline Patient No. & Age (y) & Sex & $\begin{array}{c}\text { Time from initial } \\
\text { operation to reoperation (y) }\end{array}$ & Indications for reoperation \\
\hline 1 & 69 & Male & 6 & $\begin{array}{l}\text { Redissection of the aortic root with concomitant second-degree aortic } \\
\text { valve regurgitation and aortic arch aneurysm }\end{array}$ \\
\hline 2 & 77 & Female & 5 & $\begin{array}{l}\text { Redissection of the aortic root with concomitant third-degree aortic valve } \\
\text { regurgitation, aortic arch aneurysm }\end{array}$ \\
\hline 3 & 39 & Male & 2 & $\begin{array}{l}\text { Aneurysmatic aortic root with concomitant second-degree aortic valve } \\
\text { regurgitation and redissection of the proximal aortic arch and innominate } \\
\text { artery }\end{array}$ \\
\hline
\end{tabular}

TABLE 2. Intraoperative data

\begin{tabular}{ccccc}
\hline Patient No. & Cardiopulmonary bypass time (min) & Aortic crossclamping time (min) & Circulatory arrest time (min) & Cerebral perfusion time (min) \\
\hline 1 & 232 & 188 & 43 & 32 \\
2 & 242 & 161 & 50 & 40 \\
3 & 194 & 144 & 19 & 9 \\
\hline
\end{tabular}

long-term outcome of valve-sparing versus artificial composite graft aortic root replacement to conclusively judge on the value of valve-sparing aortic root reoperation after type A aortic dissection.

\section{References}

1. Bachet JE, Termignon JL, Dreyfus G, Goudot B, Martinelli L, Piquois A, et al. Aortic dissection prevalence, cause, and results of late reoperations. J Thorac Cardiovasc Surg. 1994;108:199-206.
2. Leyh RG, Schmidtke C, Bartels C, Sievers HH. Valve-sparing aortic root replacement (remodeling/reimplantation) in acute type A dissection. Ann Thorac Surg. 2000;70:21-4.

3. David TE, Feindel CM. An aortic valve-sparing operation for patients with aortic incompetence and aneurysm of the ascending aorta. $J$ Thorac Cardiovasc Surg. 1992;103:617-21.

4. Bingley JA, Gardner MAH, Stafford EG, Mau TK, Pohlner PG, Tam RKW, et al. Late complications of tissue glues in aortic surgery. Ann Thorac Surg. 2000;69:1764-8.

5. Hufnagel CA, Conrad PW. Dissecting aneurysms of the ascending aorta: direct approach to repair. Surgery. 1962;51:84-9. 